\title{
Does pediatric anesthesia cause brain damage? - Addressing parental and provider concerns in light of compelling animal studies and seemingly ambivalent human data
}

\author{
Jeong-Rim Lee ${ }^{1}$ and Andreas W. Loepke ${ }^{2}$ \\ ${ }^{1}$ Department of Anesthesiology and Pain Medicine, Anesthesia and Pain Research Institute, Yonsei University \\ College of Medicine, Seoul, Korea, ${ }^{2}$ Department of Anesthesiology and Critical Care Medicine, Children's Hospital of \\ Philadelphia, and Perelman School of Medicine at the University of Pennsylvania, Philadelphia, PA, USA
}

\begin{abstract}
Anesthesia facilitates surgery in millions of young children every year. Structural brain abnormalities and functional impairment observed in animals have created substantial concerns among clinicians, parents, and government regulators. Clinical studies seemed ambivalent; it remains unclear whether differential species effects exist towards anesthetic exposure. The current literature search and analysis attempts to unify the available clinical and animal studies, which currently comprise of $>530$ in vivo animal studies and $>30$ clinical studies. The prevalence of abnormalities was lowest for exposures $<1$ hour, in both animals and humans, while studies with injurious findings increased in frequency with exposure time. Importantly, no exposure time, anesthetic technique, or age during exposure was clearly identifiable to be entirely devoid of any adverse outcomes. Moreover, the age dependence of maximum injury clearly identified in animal studies, combined with the heterogeneity in age in most human studies, may impede the discovery of a specific human neurological phenotype. In summary, animal and human research studies identify a growing prevalence of injurious findings with increasing exposure times. However, the existing lack of definitive data regarding safe exposure durations, unaffected ages, and non-injurious anesthetic techniques precludes any evidence-based recommendations for drastically changing current clinical anesthesia management. Animal studies focusing on brain maturational states more applicable to clinical practice, as well as clinical studies focusing on prolonged exposures during distinct developmental windows of vulnerability, are urgently needed to improve the safety of perioperative care for thousands of young children requiring life-saving and quality of life-improving procedures daily.
\end{abstract}

Keywords: Anesthesia; Animal experimentation; Apoptosis; Brain injuries; Cognitive dysfunction; Infant; Neonate; Primates; Rodents.

Corresponding author: Andreas W. Loepke, M.D., Ph.D.

Division of Cardiac Anesthesiology, Department of Anesthesiology and Critical Care Medicine, Children's Hospital of Philadelphia, Philadelphia, PA 19104, USA

Tel: 1-800-879-2467, Fax: 1-2155905824, Email: pedsanesthesia@gmail.com

ORCID: https://orcid.org/0000-0003-0768-1390

Received: June 19, 2018. Accepted: July 4, 2018.

Korean J Anesthesiol 2018 August 71(4): 255-273

https://doi.org/10.4097/kja.d.18.00165

(c) This is an open-access article distributed under the terms of the Creative Commons Attribution Non-Commercial License (http://creativecommons.org/ licenses/by-nc/4.0/), which permits unrestricted non-commercial use, distribution, and reproduction in any medium, provided the original work is properly cited. 


\section{Introduction}

General anesthesia allows surgical procedures and stressful interventions to be performed in millions of young children every year. However, developing evidence, predominantly from animal studies, demonstrating structural brain abnormalities and functional impairment following anesthetic exposure, has created substantial concerns among clinicians, parents, and government regulators regarding the safety of this practice. The possibility of long-term adverse effects caused by anesthetic exposures in young children arguably has represented one of the most alarming controversies in anesthesiology [1-5]. As a result, the United States Food and Drug Administration has published a warning regarding repeated or prolonged anesthetic exposures exceeding $3 \mathrm{~h}$ in children younger than 3 years of age [6]. To provide guidance for surgical timing, anesthesiologists are therefore increasingly faced with important questions, such as whether there exists a safe exposure time or anesthetic technique and if exposures at certain ages are less injurious than at others. Furthermore, parents, increasingly aware of these concerns, more commonly request information regarding the safety of using anesthetic drugs in their young children. While results from animal studies have been alarming, emerging human studies have been seemingly more equivocal; while some have demonstrated behavioral, learning, and cognitive abnormalities following anesthetic exposures early in life, others, including a recent prospective randomized-controlled trial, have not been able to identify any specific abnormalities or neurological phenotype. Even though a biological explanation is lacking, this might seem to suggest that differential effects exist towards anesthetic exposure's effects on brain development between humans and other species. Accordingly, the present review analyzes the available animal and human literature, evaluates the body of evidence regarding their translational significance, and provides the anesthesiologist with the most current information for their discussions with parents and other clinicians regarding the potential long-term effects of anesthetic exposure in young children.

\section{Materials and Methods}

To identify animal and human studies on the effects of anesthetic exposure on the developing brain, a literature search was performed in April 2018, followed by a systematic analysis of resultant studies, as previously described [7]. Briefly, the search terms ([anesthesia or anesthetic or isoflurane or sevoflurane or desflurane or halothane or enflurane or ketamine or barbiturate or pentobarbital or benzodiazepine or midazolam or diazepam or lorazepam or propofol or dexmedetomidine or xenon] and [toxicity or cell death or apoptosis] and [neuron or brain or spinal cord]), were used for PubMed and Scopus searches, spanning the entire years from 1974 until 2017. English language articles and their references were screened for relevance and articles using animals older than 1 month of age were excluded to focus on the developing brain. Moreover, for subsequent analyses, only in vivo studies were considered to maintain clinical relevance. Eligible studies were inspected for reports of brain structural and/or functional abnormalities and were independently scored by both authors as positive if at least one abnormality, even transiently, was reported. Studies were scored as negative if all analyzed brain structural and/or functional outcomes were reported as indistinguishable from control subjects. For studies designed with separate arms to investigate multiple anesthetics, exposure times, or ages, outcomes for each arm were scored independently. Using this dichotomous approach resulted in 100\% agreement amongst the authors' assessments. To enumerate exposure times, the reported anesthetic durations were quantified as follows: for volatile agents, exposure times were either defined as the reported time of unconsciousness or as spanning from start to discontinuation of the anesthetic. For injectable drugs, exposure duration was established as either the reported duration of unconsciousness, or, for repeated anesthetic injections, the duration was defined as the cumulative multiple of the respective inter-injection intervals. Any studies using single injectable anesthetic exposures that lacked any reported durations of sedative effects and studies specifically reporting that sedation did not reach the level of anesthesia were excluded from subsequent exposure time analysis. To examine the effect of age on subsequent outcomes, the animals' reported age during exposure for each study was converted to the corresponding maturational stage of the human brain by using a previously described computational neurodevelopmental model [8-10]. The respective species' process of neurogenesis for the whole brain was translated to the human brain (www.translatingtime.net, accessed 4/10/2018). If repeated exposures were performed at different ages, the median age of exposure was utilized. Outcomes were then dichotomized into negative or positive, as described above.

\section{Results}

Most studies on the effects of anesthetic exposure on the developing brain have been performed in animals. Using the described search strategy identified a total of $n=532$ relevant laboratory studies on the effects of anesthetics on the developing brain, published between 1974 and 2017 (Fig. 1). The number of publications has risen dramatically over the past two decades, with interest in the topic expressed in review articles, editorials, opinion papers, and letters growing even more rapidly over the years (Fig. 1). Research has been performed in a wide vari- 


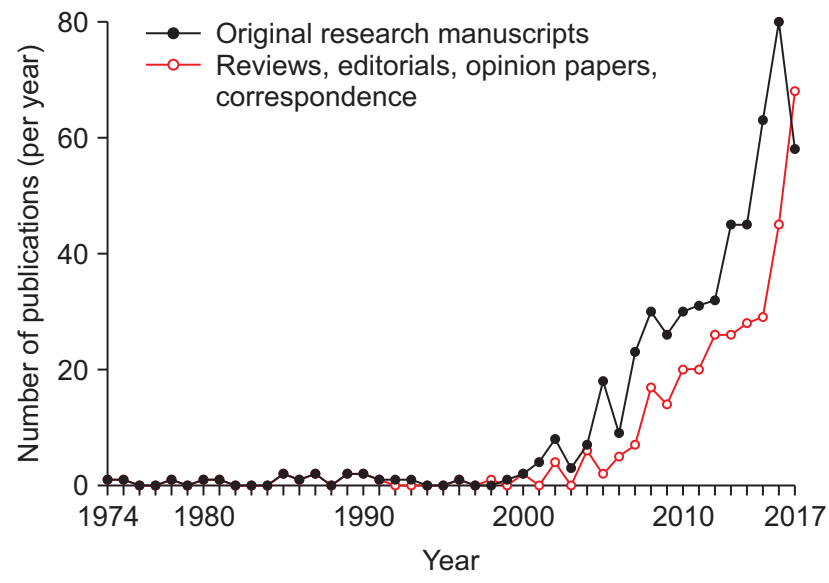

Fig. 1. Research articles investigating the effects of anesthetic exposure on the developing animal brain and commentaries have increased significantly over the past 48 years. The number of animal studies (filled black circles), as well as review articles, editorial views, commentaries, opinion papers, and correspondence on this topic (unfilled red circles) that have been published annually, as identified in a literature search using PubMed and Scopus databases, are shown spanning from 1974 until 2017.

ety of species, including chicks, mice, rats, guinea pigs, swine, sheep, and rhesus monkeys, with many studies describing brain structural and functional abnormalities following exposure to all commonly utilized general anesthetics. The most frequently studied general anesthetic was isoflurane (32\% of studies), followed by sevoflurane (25\%), ketamine (21\%), propofol (14\%), desflurane $(3 \%)$, nitrous oxide, midazolam, halothane, diazepam, enflurane, xenon, lorazepam, chloral hydrate, pentobarbital, thiopental, and phencyclidine. While historically concerns about neurological outcomes were raised for critically ill neonates requiring surgical procedures very early in life, more recently, mostly epidemiological studies on long-term neurological outcomes in healthier patient populations has been increased (Table 1).

Fig. 2 delineates laboratory and clinical studies demonstrating structural and/or functional abnormalities (positive studies) or not finding any abnormalities (negative studies), relative to cumulative exposure times, which ranged from 10 minutes to 31.5 hours. The prevalence of positive findings increases with the duration of exposure, interestingly, to a comparable degree in both animals and humans. Fig. 3 depicts positive and negative animal and human studies, as they relate to the maturational equivalency of the human brain during exposure. While preclinical studies predominantly focused on premature stages of brain development and clinical studies on postnatal stages, no distinct changes in the prevalence of positive studies were observed with increasing age, either in animals or in humans. While this would suggest that no clear age could be identified to be completely devoid of positive findings, the number of animal studies for maturational stages equivalent to children beyond one year of age was limited.

\section{Discussion}

\section{Does anesthetic exposure harm the human brain?}

Despite a rapidly evolving body of clinical and preclinical studies, it is currently impossible to answer this question with certainty. It remains unresolved whether cognitive abnormalities observed in clinical studies are caused by comorbidities, pain, inflammation, surgery, or genetic predisposition and are therefore merely associated with anesthetic exposures, rendering anesthesia as an indicator for children susceptible to neurological impairment, or whether anesthetics molecularly trigger abnormalities, representing causation. Importantly, the similarity in increasing prevalence of positive findings between human and animal studies and the structural abnormalities observed in a wide variety of animal species, including non-human primates, suggest that additional studies both in children utilizing more prolonged exposures, as well as animal studies with specifically targeted brain maturational equivalency, are urgently needed.

\section{What are the structural abnormalities observed in animals, and has an exposure threshold been identified below which no injuries occur?}

Brain tissue analysis in animals immediately following anesthetic exposure has found a variety of abnormalities, including downregulation of trophic and neurogenic factors [46,47], endocrine disruption [48], elimination and interference with the formation of synapses [49], alterations in dendritic arborization [50,51], impediment to formation of new neurons and their axonal growth [52], as well as diminished viability of brain cells, such as neurons [53], glial cells [54], and oligodendrocytes [55]. It is currently unclear whether all structural abnormalities are caused by the same mechanism and would therefore represent a continuum on a dose-response relationship or whether they are unrelated phenomena involving distinct molecular pathways. Even though there exists substantial heterogeneity in species, drugs, outcome measures, a cautious analysis, dichotomizing positive and negative results, suggests a dose/exposure time-response relationship, by demonstrating an increase in the number of studies finding a structural and/or functional deficit with increasing exposure times (Fig. 2). Importantly, however, widespread neuronal cell death has also been detected in mice following a 1-hour exposure to isoflurane [56] and in non-human primates following exposures as short as 3 hours [57], suggesting that some form of structural alteration more likely than not also occurs in children undergoing anesthetic exposures of prolonged duration. The functional relevance of these immedi- 


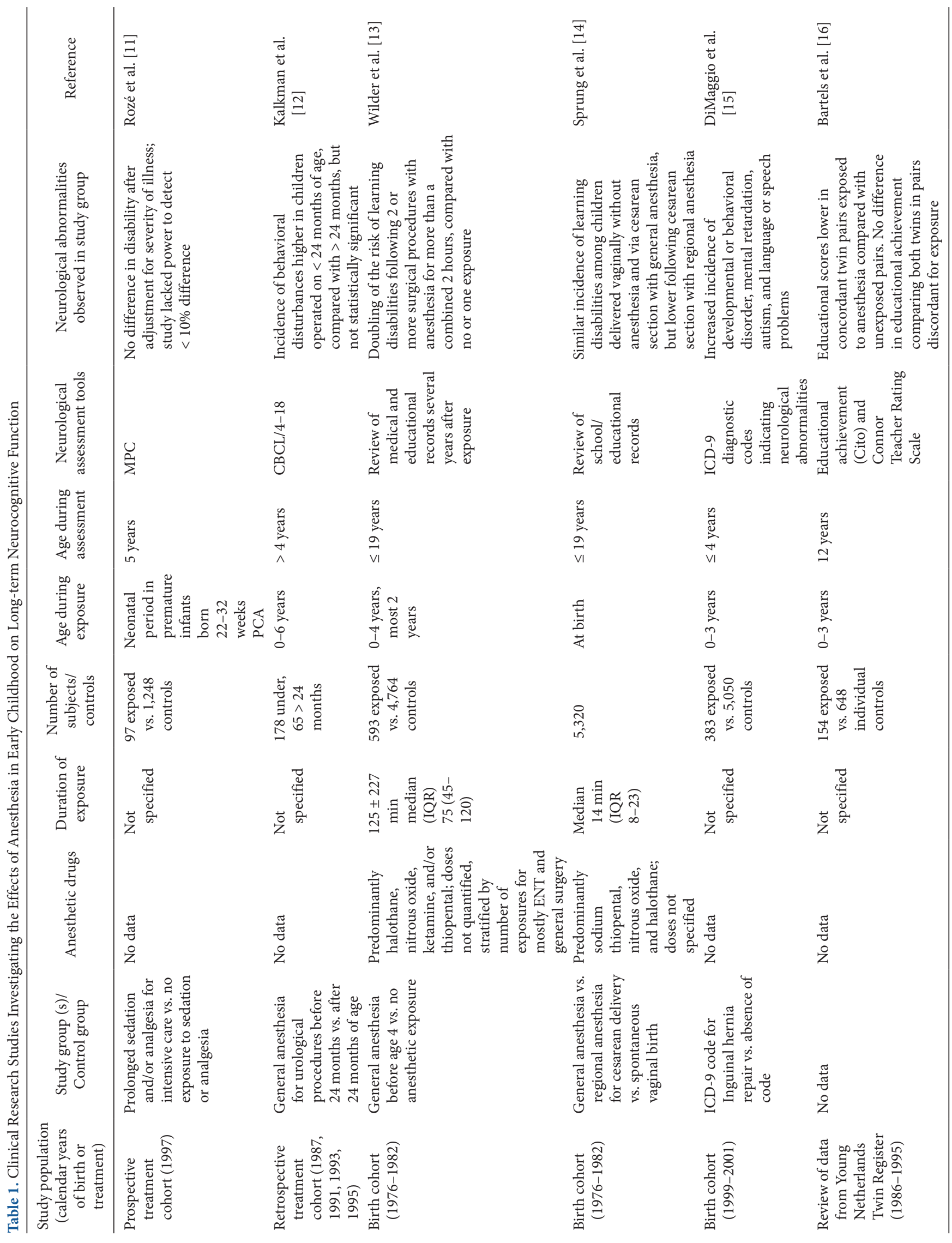




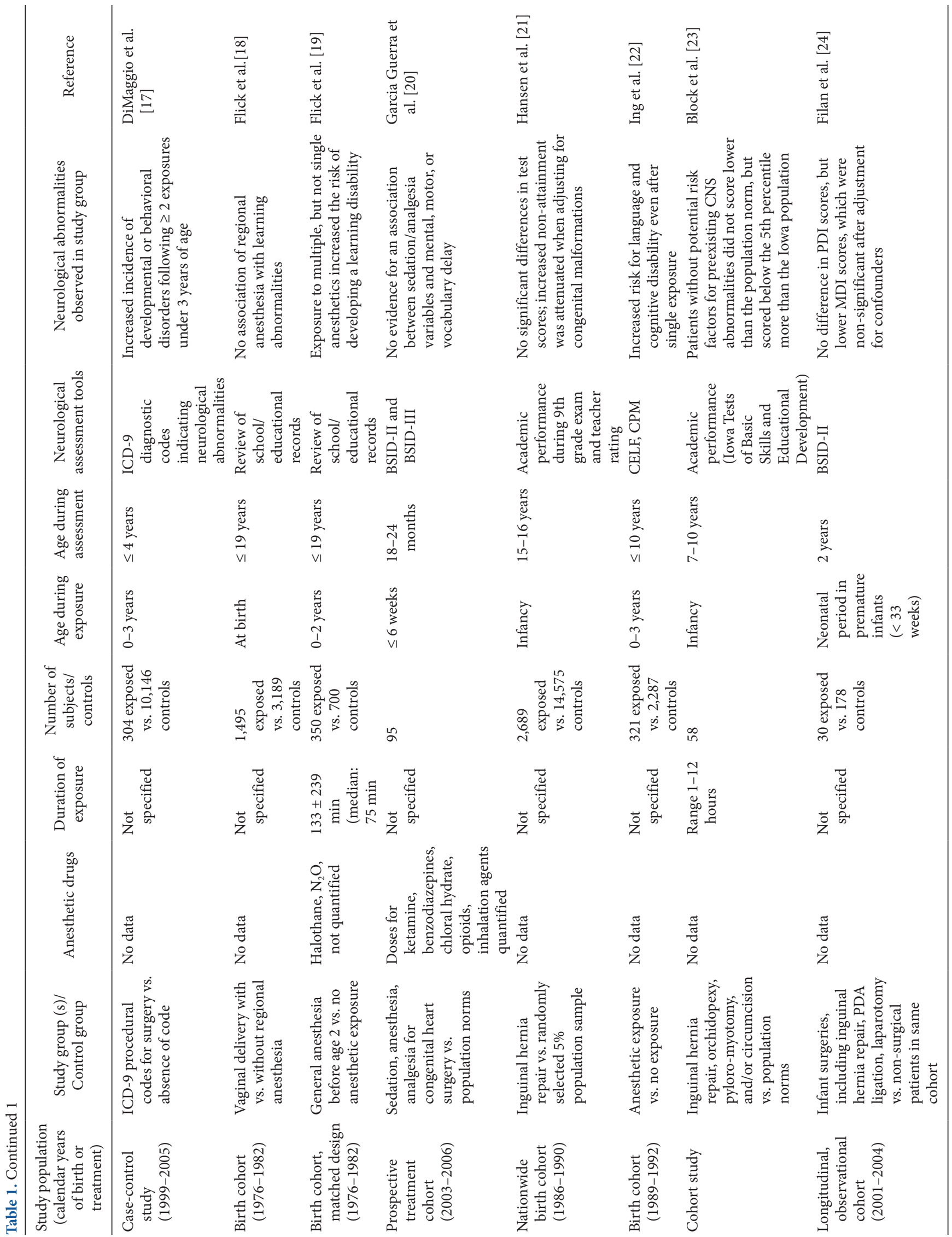




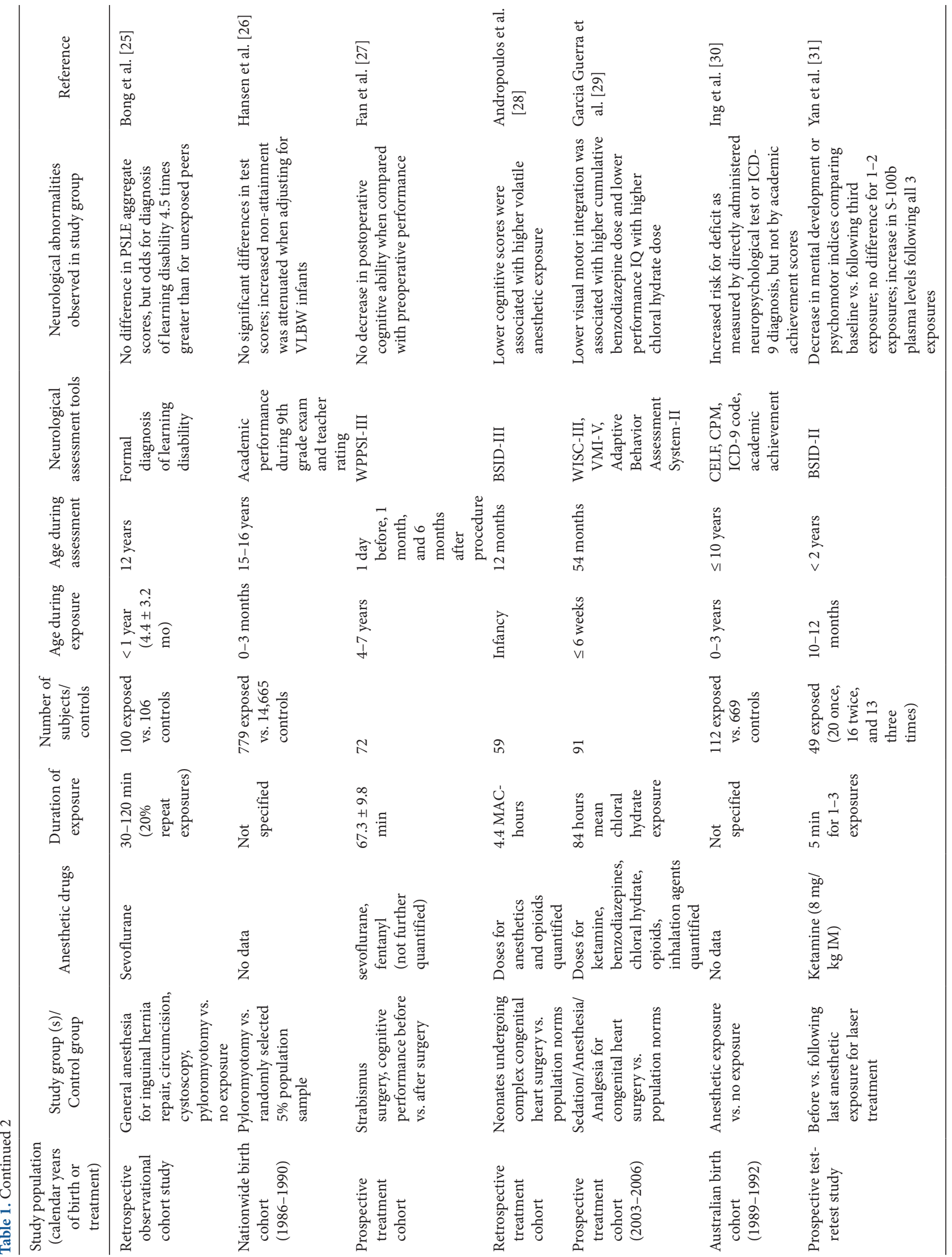




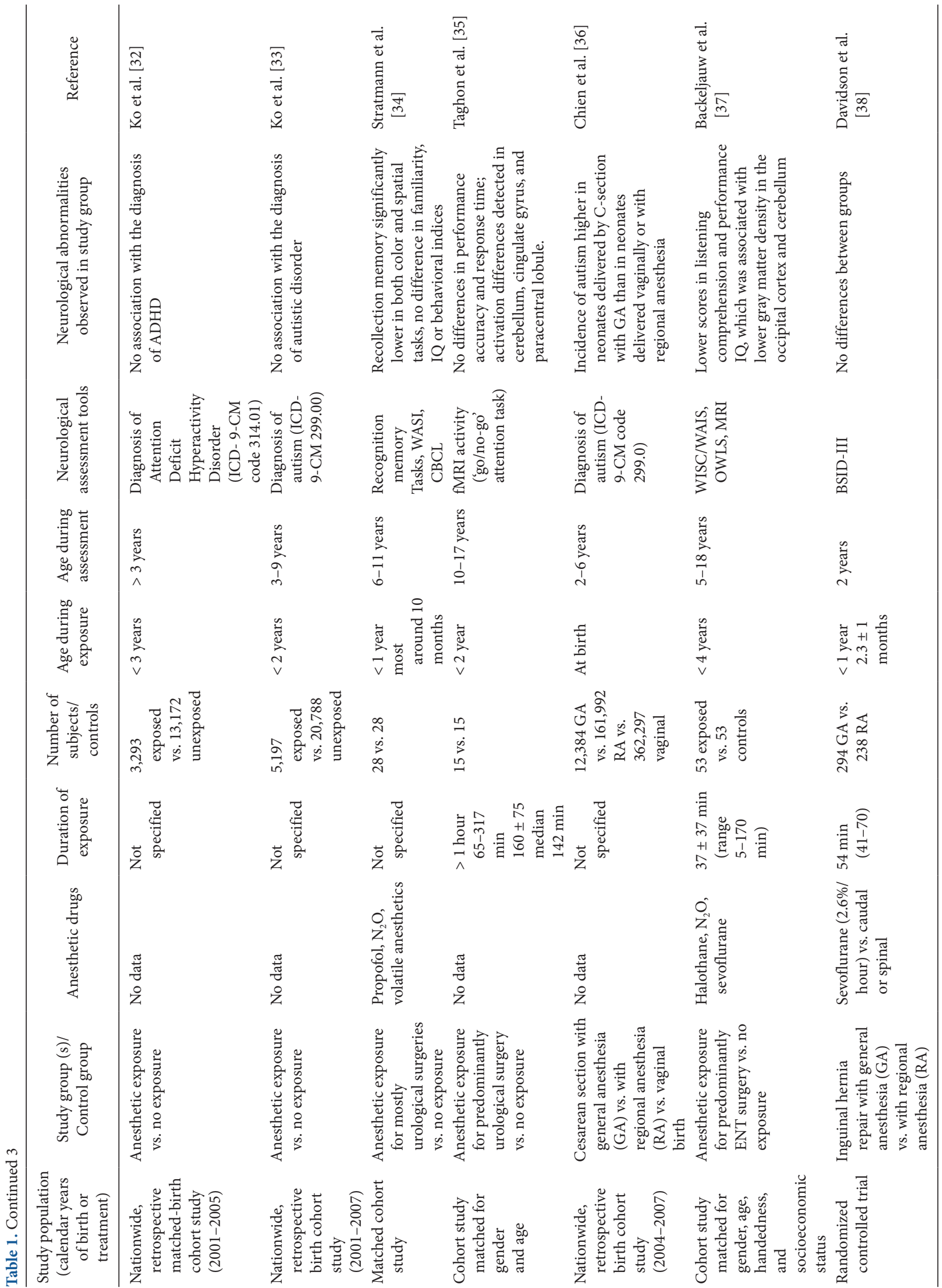




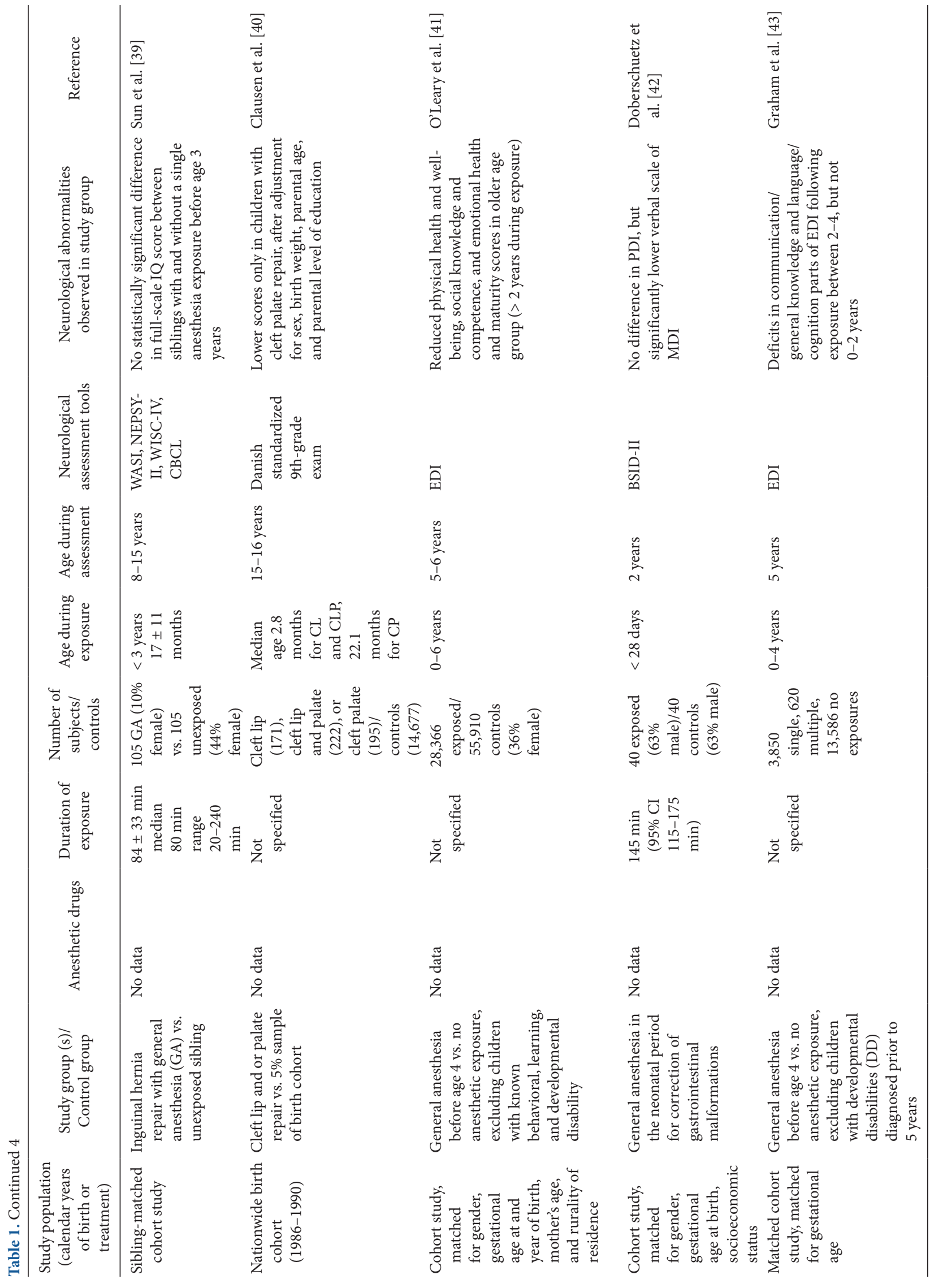




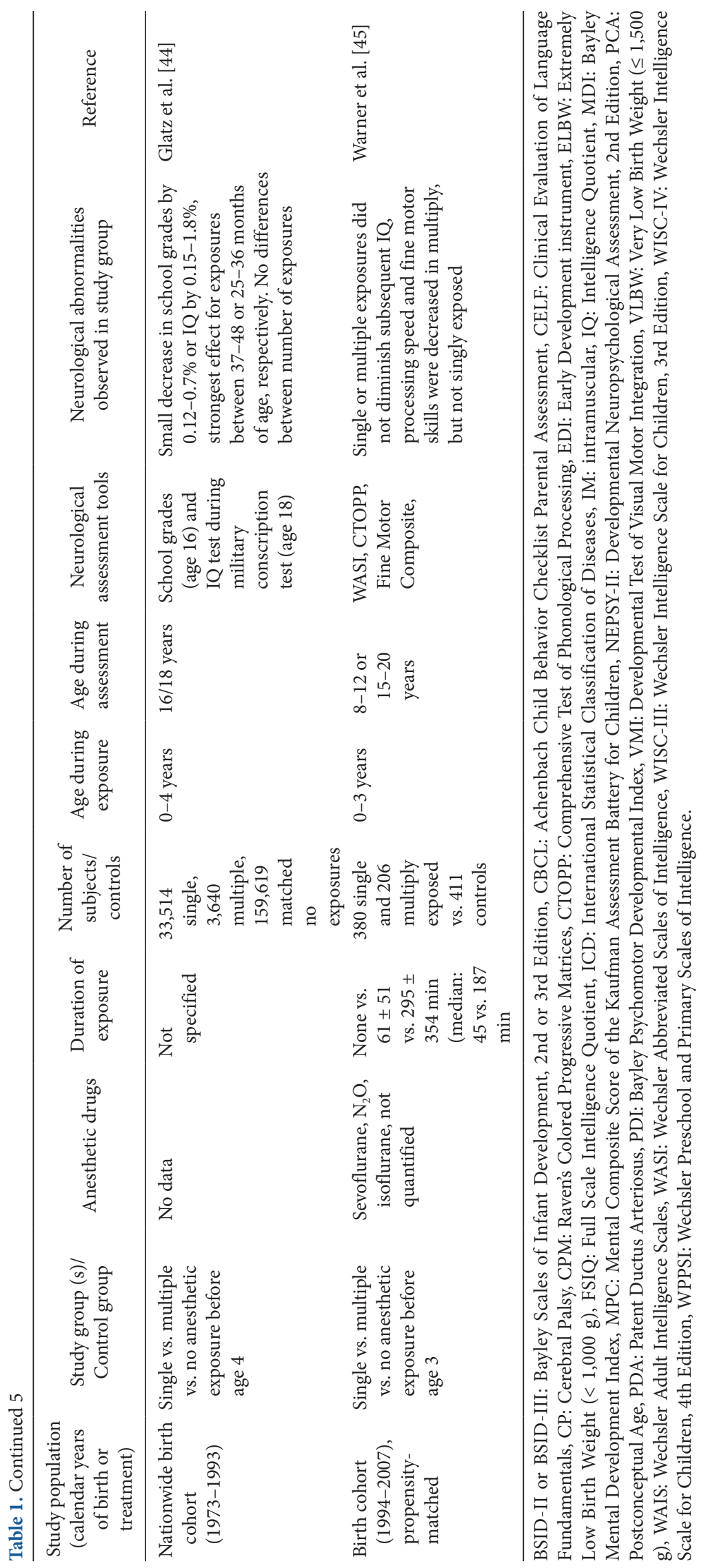




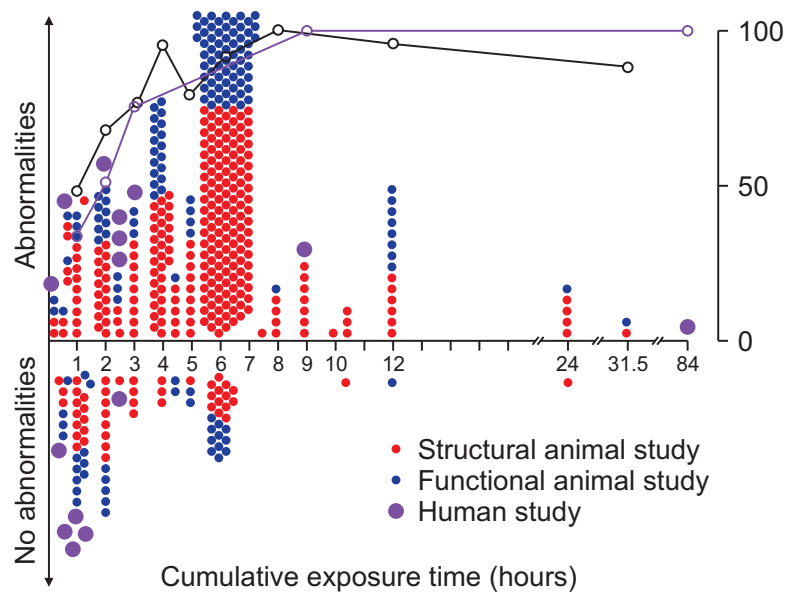

Fig. 2. The majority of in vivo animal studies on the effects of anesthetic exposure on brain structure and function examine exposure times greater than occurring during routine clinical care. However, the prevalence of both animal and human studies returning positive findings, thereby suggesting potential injury, increases similarly with exposure time. Animal studies reporting abnormal findings are depicted above the horizontal line and negative findings are shown below the horizontal line, for both brain structural (red filled circles) or cognitive outcomes (blue filled circles), as a function of exposure time. Purple filled circles represent clinical studies into long-term cognitive outcomes in humans demonstrating abnormalities (above horizontal line) or no abnormalities (below horizontal line). Exposure times denote all reported anesthetic durations, either single or cumulative, or estimated exposure times based on injection schema, as described in the methods; accordingly, only studies reporting exposure times or injection schemata were included in the analysis. For the purpose of analysis, results are reported separately for each condition or outcome studied, and therefore single studies may be represented by multiple data points. Graphs express the ratio of positive to negative studies in animals (black) and humans (purple); open circles represent percentage of positive studies for respective exposure epochs between data points. Positive studies outnumber negative studies for all exposure times in both animals and humans, except for anesthetic exposures of 1 hour or less.

ate structural changes, however, remains controversial and will be discussed in more detail below.

\section{Does animal research demonstrate all general anesthetics to be similarly toxic or are some drugs safer to use than others?}

Several studies have compared inhaled anesthetics with each other to establish whether one is safer to use than others, most frequently using neuronal cell death or dendritic alterations as the studied endpoints. Results have been conflicting, with some studies finding desflurane to cause more cell death than isoflurane or sevoflurane [58], while others found a lack of effect on dendritic spine density by desflurane [59]. One study demonstrated isoflurane to be more deleterious than desflurane [60], while another study showed isoflurane to cause greater neurodegeneration than sevoflurane, albeit without neurocog-

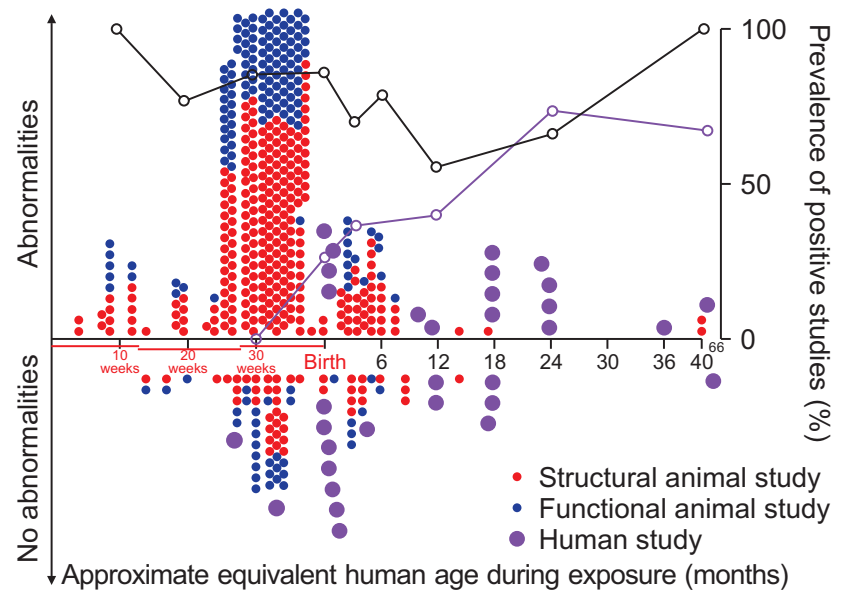

Fig. 3. The majority of in vivo animal studies on the effects of anesthetic exposure on brain structure and function focus on brain developmental stages equivalent to premature neonates. For animals, prevalence of positive studies outnumber negative studies for all age brackets, suggesting that no age can be clearly identified at which anesthetics do not cause abnormalities. Animal studies reporting abnormal findings are depicted above the horizontal line and negative findings are shown below the horizontal line, for both brain structural (red filled circles) and cognitive outcomes (blue filled circles), as a function of maturational age of the animals' brain relative to the human brain during exposure. Purple filled circles represent clinical studies into long-term cognitive outcomes in humans. The animals' age during exposure was converted to the corresponding maturational stage of the human brain based on a computational neurodevelopmental model [8-10] (www.translatingtime. net, translating 'neurogenesis' for 'whole brain', last accessed 4/1/2018). For the purpose of analysis, reports with separate anesthetic protocols consisting of different anesthetic regimens or multiple exposure times of the same anesthetic were classified as separate studies. For repeated exposures at different ages, the equivalent mean age of the human brain is reported. Graphs express the ratio of positive to negative studies in animals (black) or humans (purple); open circles represent the respective percentage of positive studies for age epochs ranging from specific data points to the next lower data point on the graph.

nitive consequences [61]. In our laboratory, after establishing equal potencies, desflurane, isoflurane, and sevoflurane created comparable increases in executioner caspase-activation and indistinguishable rates of neuronal degeneration following 6-hour exposures, suggesting that none of the currently most frequently utilized volatile anesthetics can be recommended over others [62]. Studies using injectable anesthetics, such as ketamine, propofol, midazolam, or thiopental, are even more difficult to interpret, since continuous drug administration is challenging in small animals and doses based on body weight required to anesthetize small animals are exponentially higher than in humans and outside the range of clinical practice, due to biochemical and pharmacokinetic species differences. Moreover, no clearly superior injectable anesthetic has been identified. Most recently, the experimental neuroactive steroid $3 \beta-\mathrm{OH}$ has demonstrated anesthetic properties without neurotoxicity [63]. In summary, animal studies into comparable neurotoxicity have demonstrat- 
ed widely conflicting results; therefore, no general anesthetic was consistently identified to be safer than others. Accordingly, no recommendations for clinical practice can be made for choosing one anesthetic agent over another. However, the sedative dexmedetomidine seems to cause substantially lower rates of neuronal demise than sevoflurane, even in higher doses [64]. While it doesn't provide the same level of anesthesia compared with general anesthetics [64], dexmedetomidine could still be used to decrease the dose of injurious anesthetics and for neuroprotective purposes.

\section{What might explain the specific vulnerability of the developing brain to the anesthetics' deleterious effects?}

The distinct vulnerability of very young animals demonstrated in numerous studies raises the question whether it is caused by the milieu in the young brain rendering all brain cells more susceptible to anesthetic side effects or rather if anesthetic drugs specifically target very distinct stages and signaling pathways during brain development, thereby triggering adverse effects in very defined cell populations. Further elucidating this question will be critically important for identifying potentially susceptible stages of human brain development, for developing targeted mitigation strategies, and for devising safer anesthetic techniques for patients of all ages. In this discussion, it is important to acknowledge that dramatic structural changes occur naturally in the developing brain, including massive brain cell death, which represents an integral part of normal brain development, as 50\% of all neurons formed in the developing brain do not survive into adulthood. Work in our laboratory aimed at better delineating the maturational stage-specific vulnerability has identified the late progenitor/early immature neuronal stage as specifically susceptible to anesthesia-induced neuronal cell death (Fig. 4) [65]. Importantly, we were able to demonstrate that even in the developing brain, relatively mature neurons were not susceptible to neuronal cell death [65].

As a result, the observed degree of brain regional vulnerability varies in accordance with the extent of regional neurogenesis, rendering brain regions with earlier peaks in neurogenesis more vulnerable at an early age, while susceptibility of regions peaking at a later stage was concomitantly delayed (Fig. 5) [66]. Similarly, dendritic abnormalities during anesthetic exposure are highly dependent on the age during exposure [50].

These findings convincingly demonstrate that not all neurons are indiscriminately affected during anesthetic exposure, which would argue against the developing milieu being the culprit for structural changes. Rather, anesthetics seem to trigger or block developmentally encoded processes in neurons of a very specific stage of cellular development. In order to better instruct clinical care, it will be imperative to identify the equivalent cellular populations in young children to better delineate their role and fate in order to identify a clinical phenotype.

\section{What are the long-term cognitive consequences of} anesthetic exposure in immature animals and how do they relate to the immediate structural abnormalities?

While the brain structural abnormalities following prolonged anesthetic exposures in animals are dramatic and concerning, the functional consequences are probably of even greater translational relevance to pediatric anesthesia practice, since histological comparisons between animals and humans cannot be performed. However, this field of research is hindered by the differences in neurological performance among species. Several animal studies have evaluated spontaneous behavior, tested performance in memory tasks, or assessed response to stressors in adult animals exposed to anesthetics early in life and have repeatedly found abnormalities compared with unexposed controls [34,67-69]. However, an anesthesia-specific cognitive phenotype has yet to be identified, even in animals, and not all cognitive tasks testing similar neurological domains have consistently found deficiency, even within the same study [67]. Moreover, the immediate and long-term structural correlates underlying long-term cognitive abnormalities remain unclear. It seems compelling to attribute learning impairment in adult an-

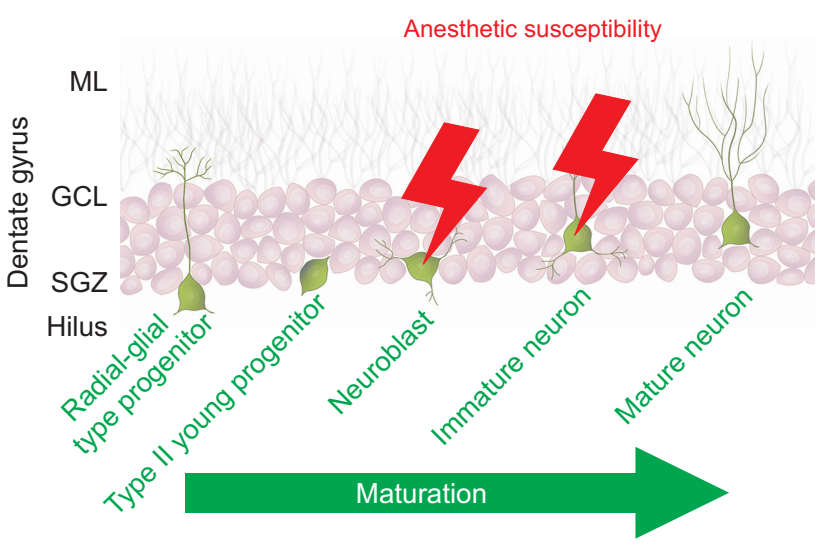

Fig. 4. Neurons during intermediate stages of their development are specific targets of anesthesia-induced apoptosis During the continuum of neuronal maturation in the dentate gyrus, a brain region with lifelong neurogenesis in rodents, isoflurane triggers apoptotic cell death in neuroblasts and immature neurons residing in the neurogenic niche, the subgranular zone (SGZ), but not in more immature radial-glial type and type II progenitors, or in mature neurons, which reside in the granule cell layer (GCL) and extend dendrites into the molecular layer (ML). Data are derived from Hofacer et al. [65]. The illustration depicts five representative stages of neuronal maturation throughout the life cycle from a pluripotent radial-glial type progenitor cell on the left to a postmitotic, mature neuron on the right. Cells at these various stages coexist in the postnatal dentate gyrus. 

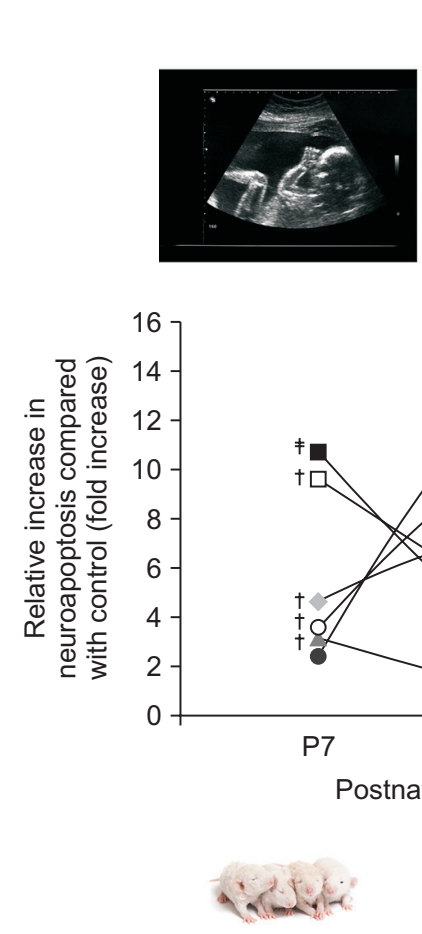
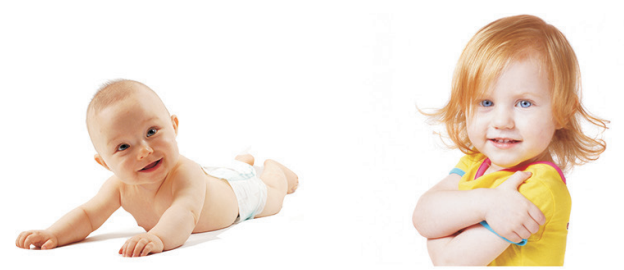

Retrosplenial cortex (RSA)

$\square$ Caudoputamen $(\mathrm{CPu})$

- Cornu ammonia (CA1)

Cerebellum $(\mathrm{Cb} / \mathrm{Cb}$ wm)

- Dentate gyrus (DG)

- Olfactory bulb (GrO)

Fig. 5. Brain regional vulnerability to anesthesia-induced neuroapoptosis changes with age during exposure. Graphs indicate the relative increase in neuronal cell death observed at three different ages following isoflurane exposure, relative to physiological apoptotic cell death observed in littermate controls. Apoptotic neuronal density was quantified in superficial layers II/III of the retrosplenial agranular cortex (RSA), caudoputamen (CPu), the pyramidal layer of cornu ammonis 1 (CA1), cerebellum ( $\mathrm{Cb}$ at P7, CB wm at P21), the subgranular zone and granule cell layer of dentate gyrus (DG), and the granule layer of the olfactory bulb (GrO) after a $6 \mathrm{~h}$ exposure to $1.5 \%$ isoflurane in newborn (P7), juvenile (P21), and adult mice (P49), compared with fasted, unanesthetized littermates [66]. Maximum vulnerability was observed in the neocortex, caudoputamen, and cornu ammonis 1 at P7, whereas the number of vulnerable neurons peaked at P21 for the cerebellum, dentate gyrus, and granule layer of the olfactory bulb. The murine brain's maturational stage at P7 approximates the premature human brain, at P21 the infant brain, and at P49 the older child's or adolescent brain [10]. ${ }^{*} \mathrm{P}<0.05,{ }^{\dagger} \mathrm{P}<0.01,{ }^{\ddagger} \mathrm{P}<0.001$ compared with control. Adapted from Deng et al. [66].

imals to neuronal deletion in brain regions utilized for learning and memory tasks, such as the hippocampus. However, we and others have found that extensive neuronal cell death can occur in immature mice immediately following anesthetic exposure in this region, without observing long-term spatial learning impairment [70]. This could be explained by the fact that in some animals even substantial cell death immediately following isoflurane exposure does not translate into long-term diminished neuronal densities [70,71]. Accordingly, permanent neuronal deletion and adult cognitive impairment were both found in rats following a neonatal exposure to isoflurane, nitrous oxide, and midazolam $[67,72]$. It is unclear whether differences in anesthetic regimens or species contributed to the discrepant findings. Another explanation could be that the total number of eliminated cells may not be the determining factor, but rather the effectiveness of the repair process, or that structural abnormalities of synapses or dendrites determine functional impairment, rather than cellular demise.

In summary, the structural correlate occurring immediately following neonatal anesthesia that underlies long-term cognitive abnormalities remains unresolved. Potential candidates may include neuronal cell death, synaptic dissolution, or dendritic abnormalities. However, it is unclear whether these have to be specific to a particular brain region. Resolving this conundrum will be critical in improving our understanding of the underlying mechanisms of anesthetic neurotoxicity and for devising mitigating strategies.

\section{How do the vulnerable maturational phases observed in animals translate to human brain developmental stages and can an age be identified beyond which no injury occurs?}

Since i) no biological tenet categorically exempts humans from the brain structural abnormalities observed following anesthetic exposures in animals and ii) structural abnormalities have been found to vary substantially with age and/or the maturational stage of the animal's brain during exposure, it is 
imperative to better categorize the equivalent stages of human brain development compared with animal studies. Even though it is impossible to perform histological analyses in healthy human brain tissue equivalent to animal studies, for obvious ethical reasons, it seems more likely than not that some structural changes consistent with those observed in animals, including non-human primates, also occur in children undergoing prolonged anesthetic exposures. However, since it is unclear which structural abnormalities cause functional impairment or translate to human cognition, it is important to consider all abnormalities equally as potential candidates for cognitive or behavioral deficits in humans. Accordingly, Fig. 3 shows the prevalence of animal and human studies demonstrating any structural or functional abnormalities following anesthetic exposure, relative to the maturational equivalent state in humans. While brain development substantially differs in regional and temporal trajectories between humans and any other species and the analysis therefore represents somewhat of a generalization, this graph nonetheless illustrates that the developmental stages most frequently studied in animals correlate to immature phases of human brain development and less to older children. However, as an extension of our previous findings of developmental stage-dependent vulnerability, we were able to demonstrate in rodents that immature neurons in brain regions with ongoing neurogenesis, such as the olfactory bulb and hippocampus, are subject to isoflurane-induced neuronal cell death even into young adulthood, and potentially throughout life (Fig. 5) [66]. Other groups have similarly detected neuronal cell death following propofol exposure in the hippocampus of adult animals [73].

These findings convincingly demonstrate that detrimental effects of prolonged anesthetic exposure are not specific or limited to the immature brain, but also occur in the adolescent or young adult brain, albeit in different brain regions than in very young animals and to a different degree, making it impossible to advise clinical practice regarding a safe age beyond which prolonged anesthetic exposure will not cause any detrimental brain abnormalities. However, these findings nonetheless explain the profound vulnerability of the immature brain, due to its overabundance of immature neurons. Importantly, this would indicate that different neurological tasks could be targeted at different ages, specifically, during their developmental windows of acquisition, as it involves amplified neurogenesis, which exposes this amplified population of immature neurons to anesthesia-induced neurotoxicity. Interestingly, while it has frequently been assumed that exposures in infancy would be most prone to causing long-term brain developmental impairment, two recent large studies concluded that school readiness scores, as assessed with the Early Development Instrument in kindergarteners, were lower in children who had been exposed to anesthesia as toddlers between 2 and 4 years of age, but not in children exposed under 2 years of age $[41,43]$. This suggests that anesthetic exposures at different ages may lead to diverse neurological deficits, dependent on which neurological skills were being acquired during exposures. This may explain the equivocal results from human studies with diverse age groups and may also help explain the exaggerated effects of multiple exposures during different windows of vulnerability.

\section{What is the current evidence for the effects of anesthetic exposures on the developing human brain and is it consistent with evidence obtained in animal studies?}

Several studies have now been performed specifically examining the effects of anesthetic exposures early in life on subsequent behavior and cognitive performance in humans (most recently reviewed in [74]). The majority of these studies have been large- to medium-scale epidemiological studies, which due to their retrospective nature are unable to distinguish between the anesthetic exposure and perioperative physiological derangements, including blood pressure fluctuations, pain, inflammation, inadequate or excessive depths of anesthesia, or co-morbidities. Studies can broadly be divided into three categories, depending on their endpoints: those measuring academic achievement with group-administered tests, those using diagnoses of learning abnormalities or need for remedial services, and those employing individually administered neuropsychological tests [75]. Thus far, the field only includes one randomized controlled trial, the GAS study [38], which has not found any neurological abnormalities compared with a regional anesthetic technique, and two ambi-directional studies combining historical anesthetic exposures with prospective cognitive testing, the PANDA and MASK studies [39,45], which found no abnormalities compared with an unexposed siblings or unexposed peers, respectively, following a single anesthetic exposure. However, these single exposures were largely limited to under 1 hour and it remains questionable whether these results can be extrapolated to more prolonged exposures. Importantly, the MASK study's multiple exposure group demonstrated processing speed and fine motor abnormalities as well as reported problems related to executive function, behavior, and reading following a median cumulative exposure time of greater than 3 hours [45]. Similarly, several other epidemiological studies have found repetitive and prolonged cumulative exposures for surgery early in life to lead to more frequent diagnosis of behavioral abnormalities, diminished academic achievement, and subpar performance in neurocognitive tests (Table 1).

In the frequently studied population of Olmsted County in Rochester, Minnesota, researchers at the Mayo Clinic have repeatedly demonstrated that multiple, but not single anesthetic 
exposures can increase the risk of learning disabilities [13,19]. Another birth cohort used to determine the long-term effects of anesthesia is the Western Australian Pregnancy Cohort (Raine), which demonstrated no diminution in academic achievement, but an increased risk for ICD-9-based diagnosis codes for cognitive and language disorders, as well as deficits in directly administered language tests following a single, prolonged exposure during the first three years of life [22,30,76,77]. Accordingly, our analysis found that the prevalence of brain structural or functional abnormalities increases with increased exposure times, both in animals and in humans (Fig. 2).

\section{What are the similarities and important differences between humans and animals as they relate to long- term effects of anesthetics in the developing brain?}

Animal studies, even in non-human primates, are fundamentally different from clinical pediatric anesthesia practice [78], as all animals are healthy subjects, whereas children requiring surgery and diagnostic studies with anesthesia oftentimes suffer from significant co-morbidities. Laboratory studies also very infrequently include painful stimulation or surgical trauma during exposure, which could potentially exacerbate or mitigate injury caused by anesthetics. Importantly, animals are frequently of very similar age during exposure and some rodent studies involve genetically identical subjects, while clinical practice accompanies high variability in genetic background and wide age ranges, which may significantly affect outcomes and complicates translational relevance of animal studies. While absolute doses for inhaled anesthetics utilized in animals are comparable to pediatric anesthesia, much higher doses of injectable anesthetics are required to anesthetize small animals compared with those used in clinical practice. Moreover, exposure times in the laboratory are frequently outside of the exposure durations seen during routine clinical practice and human studies. However, complicating these species comparisons of anesthetic durations is the question whether exposure times should be expressed as a fraction of life expectancy, or whether other comparison metrics, such as neuronal cell cycle, should be utilized. The former would result in substantially greater relative durations in small animals, due to their shorter life expectancy, whereas the latter renders exposures much more comparable between humans and animals.

Importantly, it remains challenging to equate brain maturational stages of study animals to the corresponding periods of human brain development. This is a crucial point, since animal studies have demonstrated age during exposure to critically affect regional distribution of structural abnormalities [50,65]. Moreover, more recent work in animals and the collation of clinical and preclinical literature here strongly suggest that ab- normalities may occur in animals even after the equivalent stage for 3-year-old humans [66]. Accordingly, it is very conceivable that exposures during critical windows of brain development may affect different developmental milestones and therefore may result in different neurological phenotypes, dependent on the neurological skill under development. This important aspect has yet to be better addressed in clinical studies by investigating patient cohorts that are more homogeneous in their age during exposure.

\section{What are the putative mechanisms underlying anesthetic neurotoxicity and the alleviating strategies tested in animals and can they be instantaneously implemented in clinical practice?}

The exact mechanism of anesthesia-induced disruption of brain development remains undetermined. Accordingly, any alleviating strategy that has been tested to date may not specifically target the main neurotoxic mechanism or mitigate all deleterious effects, as different structural effects and functional abnormalities may be caused by different mechanisms. Moreover, the majority of strategies leading to diminished neuronal cell death immediately following exposure have not been tested regarding functional integrity later in life. At the same time, it is unclear which functional outcome in animals is most relevant for children undergoing anesthesia early in life. This represents a major obstacle to devising and testing mitigating approaches in children. Several hypotheses have been put forward on the mechanism underlying anesthetic neurotoxicity [79]; the most prevailing assumptions have been that the anesthetics' NMDA receptor-blocking and $\mathrm{GABA}_{\mathrm{A}}$ receptor-stimulating properties may cause abnormal neuronal inhibition, which leads to immediate neuronal demise and long-term cognitive abnormalities due to an inadequate number of neurons in adulthood. Importantly, however, any causation of NMDA and GABA-mediated effects has never been conclusively demonstrated and several studies actually refute this proposed mechanism [80,81]. Other hypotheses for anesthetic neurotoxicity include that the stimulation of $\mathrm{GABA}_{\mathrm{A}}$-receptors in immature cells may result in overexcitation; that an overactivation of inositol 1,4,5-trisphosphate receptors (InsP3Rs) may lead to excessive $\mathrm{Ca}^{2+}$ release from the endoplasmic reticulum; prolonged NMDA receptor blockade may upregulate glutamate receptor NR1 subunits, facilitating pathological calcium entry into neurons; anesthesia-induced reductions in synaptic tissue plasminogen activation (tPA) release and increases in proBDNF/p $75^{\mathrm{NTR}}$ might mediate apoptotic cell death; disruption of the neuronal cytoskeleton could lead to cellular dysfunction and death; impairment in synapse formation; and disturbance of mitochondrial metabolism may lead to anesthesia-induced neuronal cell death. Accordingly, a 
widely disparate array of drugs and compounds has been tested and demonstrated to avert anesthesia-induced neurotoxicity, such as lithium, melatonin, bumetanide, pilocarpine, estradiol, neurotrophic receptor $\mathrm{p} 75^{\mathrm{NTR}}$, vitamin C, L-carnitine, coenzyme Q10, resveratrol, pramipexole, carbon monoxide, hydrogen gas, xenon, and dexmedetomidine, to name a few. Whole body hypothermia to $24^{\circ} \mathrm{C}$ was also found to diminish neuronal cell death during anesthetic exposure. In general, since the majority of therapies employed in animals have not been thoroughly tested in children yet and because human applicability of animal data is still under investigation, none of these modalities can currently be recommended for routine clinical practice.

\section{Are there any gender differences in response to anesthetic exposure in animals or humans?}

Beginning in childhood and leading into adolescence, brain maturation differs significantly between sexes [82]. Accordingly, several animal studies have investigated whether gender differences exist in the response to anesthetic exposures. Some rodent studies have found learning and social behavior abnormalities $[83,84]$ and neurobehavioral and endocrine abnormalities $[48,85]$ subsequent to neonatal exposure to isoflurane, sevoflurane, or propofol only in male rats, but not female animals. Conversely, however, other groups demonstrated greater vulnerability in female animals, such as more acute structural damage [86], and altered adult motor activity [87], as well as adult spatial learning impairment [88]. Yet other studies have not detected any sex-related differences, such as emotional reactivity in rhesus macaque monkeys [89]. Similarly, studies in our laboratory have not found any gender differences during a complex learning task involving the Morris water maze in adult mice exposed to 6 hours of isoflurane early in life [70].

Clinical investigations into anesthetic exposures inevitably more frequently study male subjects, because boys more commonly require surgery in early childhood. Boys who underwent anesthesia in infancy, but not girls, performed worse in a longterm spatial recollection memory task, compared with unexposed gender-matched children [34]. Following neonatal cardiac surgery with general anesthesia, male gender represents a risk factor for lower mental performance in the Bailey Scales of Infant Development [90]. Importantly, however, in the general population, speech and language delay as well as mental illness are more frequently diagnosed in males, compared with females $[91,92]$, and premature male infants have worse outcomes compared with those of female gender [93]. It is therefore currently unclear, both in laboratory studies as well as in clinical practice, whether gender differences exist in the brain's response to anesthetic exposure.

Online access in http://ekja.org

\section{Should anesthesiologists proactively inform parents about this clinical concern?}

Given the warning expressed in the United States regarding the prolonged or repeated use of anesthetics for greater than 3 hours in children younger than 3 years of age, it may be required or encouraged by local jurisdictions for anesthesia providers to proactively inform parents of the concerns regarding the prolonged use of anesthetics in young children. Moreover, there may exist an ethical obligation to include pertinent information in an informed consent for general anesthesia. On the other hand, it can be argued that the lack of definitive data unequivocally and causatively linking anesthetic exposures in isolation of other stressors to neurological impairment does not warrant discussion prior to medically indicated procedures, as it would cause parents undue distress and create unjustifiable conflict whether to proceed with a required intervention out of concern for the potential risks of anesthetic effects. Accordingly, it should probably currently remain at the particular anesthesiologist's discretion whether or not to proactively address the potential long-term effects of anesthetic exposure on brain development with parents.

\section{How should anesthesiologists address concerns regarding the use of anesthetics in children, when raised by parents?}

When approached by parents, anesthesiologists should be prepared to discuss this topic in detail with the concerned guardians. This can only be accomplished if providers stay abreast of this rapidly evolving field. Obviously, not performing a necessary procedure may expose the child to substantial risks for loss of life or injury, far outweighing the concerns regarding anesthetic exposure on brain development. Parents should understand that current animal research does not justify postponing exposures until a certain age, as no safe age has been clearly identified yet. Rather, evolving animal and human research support differential effects at different ages and stages of brain development. Moreover, the best clinical evidence currently available from the GAS and PANDA studies suggests that a single, approximately 1-hour anesthetic exposure very early in life may not have any measurable effects on subsequent cognitive performance in young toddlers [38,39]. However, since these studies did not address prolonged or repeated exposure, the same statement can currently not be made with certainty regarding in these scenarios. It therefore remains important to minimize the number of procedures and exposure times as much as feasible. It is also important to note that a variety of factors, including educational experiences, probably have a greater effect on brain development than anesthetic exposures. All health care 
professionals involved in caring for a particular child should be included in any discussion regarding indication and timing of procedures requiring general anesthesia. Parental concerns should not be hastily dismissed, but should be put in the nuanced context of evolving research in a complex field. Continued research is urgently needed to better define the phenomenon, to understand its mechanisms, and to devise strategies to improve perioperative safety for children requiring lifesaving and quality of life improving procedures early in life.

\section{Conclusions}

This review finds that there currently exist more than 530 animal studies and greater than 30 clinical studies specifically investigating the effects of anesthetic exposure on the developing brain in this rapidly developing field of research. While emerging clinical studies suggest that anesthetic exposures up to 1 hour do not cause measurable abnormalities later in life, the current pre-clinical and limited clinical evidence are surprisingly consistent in demonstrating an increasing prevalence of abnormal findings with increasing exposure times. Importantly, current animal research does not support a specific exposure threshold below which no structural injury occurs. Moreover, despite the sizable body of literature, no particular anesthetic has been consistently identified to be less injurious than others to be recommended for use as a general anesthetic in young children. Animal and human data do not clearly identify a specific age beyond which anesthetic exposures are devoid of subsequent potential neurological abnormalities. This paucity of definitive information currently precludes any evidence-based recommendations for drastic changes in clinical practice and calls for concerted laboratory and clinical research efforts to further improve the safety of perioperative care for thousands of young children requiring life-saving and quality of life-improving procedures every day.

\section{Funding Statement}

National Research Foundation of Korea (NRF) grant funded by the Korea government (MSIT) (2017R1A2B4004803).

\section{ORCID}

Jeong-Rim Lee, https://orcid.org/0000-0002-7425-0462

Andreas W. Loepke, https://orcid.org/0000-0003-0768-1390

\section{References}

1. Soriano SG, Loepke AW. Let's not throw the baby out with the bath water: potential neurotoxicity of anesthetic drugs in infants and children. J Neurosurg Anesthesiol 2005; 17: 207-9.

2. Jevtovic-Todorovic V, Olney JW. PRO: Anesthesia-induced developmental neuroapoptosis: status of the evidence. Anesth Analg 2008; 106: 1659-63.

3. Loepke AW, McGowan FX Jr, Soriano SG. CON: The toxic effects of anesthetics in the developing brain: the clinical perspective. Anesth Analg 2008; 106: 1664-9.

4. Vutskits L. Anesthetic-related neurotoxicity and the developing brain: shall we change practice? Paediatr Drugs 2012; 14: 13-21.

5. Davidson AJ. Neurotoxicity and the need for anesthesia in the newborn: does the emperor have no clothes? Anesthesiology 2012; 116: 5079.

6. FDA drug safety communication: FDA approves label changes for use of general anesthetic and sedation drugs in young children [Internet]. Silver Spring (MD): U.S. Food \& Drug Administration; 2017 Apr 27 [updated 2017 May 9; cited 2018 Jun 19]. Available from www.fda.gov/ Drugs/DrugSafety/ucm554634.htm.

7. Lin EP, Lee JR, Lee CS, Deng M, Loepke AW. Do anesthetics harm the developing human brain? An integrative analysis of animal and human studies. Neurotoxicol Teratol 2017; 60: 117-28.

8. Clancy B, Darlington RB, Finlay BL. Translating developmental time across mammalian species. Neuroscience 2001; 105: 7-17.

9. Clancy B, Finlay BL, Darlington RB, Anand KJ. Extrapolating brain development from experimental species to humans. Neurotoxicology 2007; 28: 931-7.

10. Workman AD, Charvet CJ, Clancy B, Darlington RB, Finlay BL. Modeling transformations of neurodevelopmental sequences across mammalian species. J Neurosci 2013; 33: 7368-83.

11. Rozé JC, Denizot S, Carbajal R, Ancel PY, Kaminski M, Arnaud C, et al. Prolonged sedation and/or analgesia and 5-year neurodevelopment outcome in very preterm infants: results from the EPIPAGE cohort. Arch Pediatr Adolesc Med 2008; 162: 728-33.

12. Kalkman CJ, Peelen L, Moons KG, Veenhuizen M, Bruens M, Sinnema G, et al. Behavior and development in children and age at the time of first anesthetic exposure. Anesthesiology 2009; 110: 805-12.

13. Wilder RT, Flick RP, Sprung J, Katusic SK, Barbaresi WJ, Mickelson C, et al. Early exposure to anesthesia and learning disabilities in a population-based birth cohort. Anesthesiology 2009; 110: 796-804. 
14. Sprung J, Flick RP, Wilder RT, Katusic SK, Pike TL, Dingli M, et al. Anesthesia for cesarean delivery and learning disabilities in a populationbased birth cohort. Anesthesiology 2009; 111: 302-10.

15. DiMaggio C1, Sun LS, Kakavouli A, Byrne MW, Li G. A retrospective cohort study of the association of anesthesia and hernia repair surgery with behavioral and developmental disorders in young children. J Neurosurg Anesthesiol 2009; 21: 286-91.

16. Bartels M, Althoff RR, Boomsma DI. Anesthesia and cognitive performance in children: no evidence for a causal relationship. Twin Res Hum Genet 2009; 12: 246-53.

17. DiMaggio C, Sun LS, Li G. Early childhood exposure to anesthesia and risk of developmental and behavioral disorders in a sibling birth cohort. Anesth Analg 2011; 113: 1143-51.

18. Flick RP, Lee K, Hofer RE, Beinborn CW, Hambel EM, Klein MK, et al. Neuraxial labor analgesia for vaginal delivery and its effects on childhood learning disabilities. Anesth Analg 2011; 112: 1424-31.

19. Flick RP, Katusic SK, Colligan RC, Wilder RT, Voigt RG, Olson MD, et al. Cognitive and behavioral outcomes after early exposure to anesthesia and surgery. Pediatrics 2011; 128: e1053-61.

20. Guerra GG, Robertson CM, Alton GY, Joffe AR, Cave DA, Dinu IA, et al. Neurodevelopmental outcome following exposure to sedative and analgesic drugs for complex cardiac surgery in infancy. Paediatr Anaesth 2011; 21: 932-41.

21. Hansen TG, Pedersen JK, Henneberg SW, Pedersen DA, Murray JC, Morton NS, et al. Academic performance in adolescence after inguinal hernia repair in infancy: a nationwide cohort study. Anesthesiology 2011; 114: 1076-85.

22. Ing C, DiMaggio C, Whitehouse A, Hegarty MK, Brady J, von Ungern-Sternberg BS, et al. Long-term differences in language and cognitive function after childhood exposure to anesthesia. Pediatrics 2012; 130: e476-85.

23. Block RI, Thomas JJ, Bayman EO, Choi JY, Kimble KK, Todd MM. Are anesthesia and surgery during infancy associated with altered academic performance during childhood? Anesthesiology 2012; 117: 494-503.

24. Filan PM, Hunt RW, Anderson PJ, Doyle LW, Inder TE. Neurologic outcomes in very preterm infants undergoing surgery. J Pediatr 2012; 160: 409-14.

25. Bong CL, Allen JC, Kim JT. The effects of exposure to general anesthesia in infancy on academic performance at age 12. Anesth Analg 2013; 117: 1419-28.

26. Hansen TG, Pedersen JK, Henneberg SW, Morton NS, Christensen K. Educational outcome in adolescence following pyloric stenosis repair before 3 months of age: a nationwide cohort study. Paediatr Anaesth 2013; 23: 883-90.

27. Fan Q, Cai Y, Chen K, Li W. Prognostic study of sevoflurane-based general anesthesia on cognitive function in children. J Anesth 2013; 27: 493-9.

28. Andropoulos DB, Ahmad HB, Haq T, Brady K, Stayer SA, Meador MR, et al. The association between brain injury, perioperative anesthetic exposure, and 12-month neurodevelopmental outcomes after neonatal cardiac surgery: a retrospective cohort study. Paediatr Anaesth 2014; 24: $266-74$.

29. Garcia Guerra G, Robertson CM, Alton GY, Joffe AR, Cave DA, Yasmin F, et al. Neurotoxicity of sedative and analgesia drugs in young infants with congenital heart disease: 4-year follow-up. Paediatr Anaesth 2014; 24: 257-65.

30. Ing CH, DiMaggio CJ, Malacova E, Whitehouse AJ, Hegarty MK, Feng T, et al. Comparative analysis of outcome measures used in examining neurodevelopmental effects of early childhood anesthesia exposure. Anesthesiology 2014; 120: 1319-32.

31. Yan J, Li YR, Zhang Y, Lu Y, Jiang H. Repeated exposure to anesthetic ketamine can negatively impact neurodevelopment in infants: a prospective preliminary clinical study. J Child Neurol 2014; 29: 1333-8.

32. Ko WR, Liaw YP, Huang JY, Zhao DH, Chang HC, Ko PC, et al. Exposure to general anesthesia in early life and the risk of attention deficit/ hyperactivity disorder development: a nationwide, retrospective matched-cohort study. Paediatr Anaesth 2014; 24: 741-8.

33. Ko WR, Huang JY, Chiang YC, Nfor ON, Ko PC, Jan SR, et al. Risk of autistic disorder after exposure to general anaesthesia and surgery: a nationwide, retrospective matched cohort study. Eur J Anaesthesiol 2015; 32: 303-10.

34. Stratmann G, Lee J, Sall JW, Lee BH, Alvi RS, Shih J, et al. Effect of general anesthesia in infancy on long-term recognition memory in humans and rats. Neuropsychopharmacology 2014; 39: 2275-87.

35. Taghon TA, Masunga AN, Small RH, Kashou NH. A comparison of functional magnetic resonance imaging findings in children with and without a history of early exposure to general anesthesia. Paediatr Anaesth 2015; 25: 239-46.

36. Chien LN, Lin HC, Shao YH, Chiou ST, Chiou HY. Risk of autism associated with general anesthesia during cesarean delivery: a populationbased birth-cohort analysis. J Autism Dev Disord 2015; 45: 932-42.

37. Backeljauw B, Holland SK, Altaye M, Loepke AW. Cognition and brain structure following early childhood surgery with anesthesia. Pediatrics 2015; 136: e1-12.

38. Davidson AJ, Disma N, de Graaff JC, Withington DE, Dorris L, Bell G, et al. Neurodevelopmental outcome at 2 years of age after general anaesthesia and awake-regional anaesthesia in infancy (GAS): an international multicentre, randomised controlled trial. Lancet 2016; 387: 239-50.

39. Sun LS, Li G, Miller TL, Salorio C, Byrne MW, Bellinger DC, et al. Association between a single general anesthesia exposure before age 36 months and neurocognitive outcomes in later childhood. JAMA 2016; 315: 2312-20.

40. Clausen NG, Pedersen DA, Pedersen JK, Møller SE, Grosen D, Wehby GL, et al. Oral clefts and academic performance in adolescence: the impact of anesthesia-related neurotoxicity, timing of surgery, and type of oralclefts. Cleft Palate Craniofac J 2017; 54: 371-80. 
41. O'Leary JD, Janus M, Duku E, Wijeysundera DN, To T, Li P, et al. A population-based study evaluating the association between surgery in early life and child development at primary school entry. Anesthesiology 2016; 125: 272-9.

42. Doberschuetz N, Dewitz R, Rolle U, Schlösser R, Allendorf A. Follow-up of children with gastrointestinal malformations and postnatal surgery and anesthesia: evaluation at two years of age. Neonatology 2016; 110: 8-13.

43. Graham MR, Brownell M, Chateau DG, Dragan RD, Burchill C, Fransoo RR. Neurodevelopmental assessment in kindergarten in children exposed to general anesthesia before the age of 4 years: a retrospective matchedcohort study. Anesthesiology 2016; 125: 667-77.

44. Glatz P, Sandin RH, Pedersen NL, Bonamy AK, Eriksson LI, Granath F. Association of anesthesia and surgery during childhood with longterm academic performance. JAMA Pediatr 2017; 171: e163470.

45. Warner DO, Zaccariello MJ, Katusic SK, Schroeder DR, Hanson AC, Schulte PJ, et al. Neuropsychological and behavioral outcomes after exposure of young children to procedures requiring general anesthesia: the mayo anesthesia safety in kids (MASK) study. Anesthesiology 2018; 129: 89-105.

46. Lu LX, Yon JH, Carter LB, Jevtovic-Todorovic V. General anesthesia activates BDNF-dependent neuroapoptosis in the developing rat brain. Apoptosis 2006; 11: 1603-15.

47. Head BP, Patel HH, Niesman IR, Drummond JC, Roth DM, Patel PM. Inhibition of p75 neurotrophin receptor attenuates isofluranemediated neuronal apoptosis in the neonatal central nervous system. Anesthesiology 2009; 110: 813-25.

48. Tan S, Xu C, Zhu W, Willis J, Seubert CN, Gravenstein N, et al. Endocrine and neurobehavioral abnormalities induced by propofol administered to neonatal rats. Anesthesiology 2014; 121: 1010-7.

49. Sanchez V, Feinstein SD, Lunardi N, Joksovic PM, Boscolo A, Todorovic SM, et al. General anesthesia causes long-term impairment of mitochondrial morphogenesis and synaptic transmission in developing rat brain. Anesthesiology 2011; 115: 992-1002.

50. De Roo M, Klauser P, Briner A, Nikonenko I, Mendez P, Dayer A, et al. Anesthetics rapidly promote synaptogenesis during a critical period of brain development. PLoS One 2009; 4: e7043.

51. Lunardi N, Ori C, Erisir A, Jevtovic-Todorovic V. General anesthesia causes long-lasting disturbances in the ultrastructural properties of developing synapses in young rats. Neurotox Res 2010; 17: 179-88.

52. Mintz CD, Smith SC, Barrett KM, Benson DL. Anesthetics interfere with the polarization of developing cortical neurons. J Neurosurg Anesthesiol 2012; 24: 368-75.

53. Ikonomidou C, Bosch F, Miksa M, Bittigau P, Vöckler J, Dikranian K, et al. Blockade of NMDA receptors and apoptotic neurodegeneration in the developing brain. Science 1999; 283: 70-4.

54. Lunardi N, Hucklenbruch C, Latham JR, Scarpa J, Jevtovic-Todorovic V. Isoflurane impairs immature astroglia development in vitro: the role of actin cytoskeleton. J Neuropathol Exp Neurol 2011; 70: 281-91.

55. Brambrink AM, Back SA, Riddle A, Gong X, Moravec MD, Dissen GA, et al. Isoflurane-induced apoptosis of oligodendrocytes in the neonatal primate brain. Ann Neurol 2012; 72: 525-35.

56. Johnson SA, Young C, Olney JW. Isoflurane-induced neuroapoptosis in the developing brain of nonhypoglycemic mice. J Neurosurg Anesthesiol 2008; 20: 21-8.

57. Noguchi KK, Johnson SA, Dissen GA, Martin LD, Manzella FM, Schenning KJ, et al. Isoflurane exposure for three hours triggers apoptotic cell death in neonatal macaque brain. Br J Anaesth 2017; 119: 524-31.

58. Kodama M, Satoh Y, Otsubo Y, Araki Y, Yonamine R, Masui K, et al. Neonatal desflurane exposure induces more robust neuroapoptosis than do isoflurane and sevoflurane and impairs working memory. Anesthesiology 2011; 115: 979-91.

59. Briner A, De Roo M, Dayer A, Muller D, Habre W, Vutskits L. Volatile anesthetics rapidly increase dendritic spine density in the rat medial prefrontal cortex during synaptogenesis. Anesthesiology 2010; 112: 546-56.

60. Tao G, Xue Q, Luo Y, Li G, Xia Y, Yu B. Isoflurane is more deleterious to developing brain than desflurane: the role of the akt/gsk $3 \beta$ signaling pathway. Biomed Res Int 2016; 2016: 7919640.

61. Liang G, Ward C, Peng J, Zhao Y, Huang B, Wei H. Isoflurane causes greater neurodegeneration than an equivalent exposure of sevoflurane in the developing brain of neonatal mice. Anesthesiology 2010; 112: 1325-34.

62. Istaphanous GK, Howard J, Nan X, Hughes EA, McCann JC, McAuliffe JJ, et al. Comparison of the neuroapoptotic properties of equipotent anesthetic concentrations of desflurane, isoflurane, or sevoflurane in neonatal mice. Anesthesiology 2011; 114: 578-87.

63. Atluri N, Joksimovic SM, Oklopcic A, Milanovic D, Klawitter J, Eggan P, et al. A neurosteroid analogue with T-type calcium channel blocking properties is an effective hypnotic, but is not harmful to neonatal rat brain. Br J Anaesth 2018; 120: 768-778.

64. Lee JR, Lin EP, Hofacer RD, Upton B, Lee SY, Ewing L, et al. Alternative technique or mitigating strategy for sevoflurane-induced neurodegeneration: a randomized controlled dose-escalation study of dexmedetomidine in neonatal rats. Br J Anaesth 2017; 119: 492-505.

65. Hofacer RD, Deng M, Ward CG, Joseph B, Hughes EA, Jiang C, et al. Cell age-specific vulnerability of neurons to anesthetic toxicity. Ann Neurol 2013; 73: 695-704.

66. Deng M, Hofacer RD, Jiang C, Joseph B, Hughes EA, Jia B, et al. Brain regional vulnerability to anaesthesia-induced neuroapoptosis shifts with age at exposure and extends into adulthood for some regions. Br J Anaesth 2014; 113: 443-51.

67. Jevtovic-Todorovic V, Hartman RE, Izumi Y, Benshoff ND, Dikranian K, Zorumski CF, et al. Early exposure to common anesthetic agents causes widespread neurodegeneration in the developing rat brain and persistent learning deficits. J Neurosci 2003; 23: 876-82.

68. Alvarado MC, Murphy KL, Baxter MG. Visual recognition memory is impaired in rhesus monkeys repeatedly exposed to sevoflurane in 
infancy. Br J Anaesth 2017; 119: 517-23.

69. Coleman K, Robertson ND, Dissen GA, Neuringer MD, Martin LD, Cuzon Carlson VC, et al. Isoflurane anesthesia has long-term consequences on motor and behavioral development in infant rhesus macaques. Anesthesiology 2017; 126: 74-84.

70. Loepke AW, Istaphanous GK, McAuliffe JJ 3rd, Miles L, Hughes EA, McCann JC, et al. The effects of neonatal isoflurane exposure in mice on brain cell viability, adult behavior, learning, and memory. Anesth Analg 2009; 108: 90-104.

71. Jiang Y, Tong D, Hofacer RD, Loepke AW, Lian Q, Danzer SC. Long-term fate mapping to assess the impact of postnatal isoflurane exposure on hippocampal progenitor cell productivity. Anesthesiology 2016; 125: 1159-70.

72. Nikizad H, Yon JH, Carter LB, Jevtovic-Todorovic V. Early exposure to general anesthesia causes significant neuronal deletion in the developing rat brain. Ann N Y Acad Sci 2007; 1122: 69-82.

73. Krzisch M, Sultan S, Sandell J, Demeter K, Vutskits L, Toni N. Propofol anesthesia impairs the maturation and survival of adult-born hippocampal neurons. Anesthesiology 2013; 118: 602-10.

74. Davidson AJ, Sun LS. Clinical evidence for any effect of anesthesia on the developing brain. Anesthesiology 2018; 128: 840-53.

75. Lei SY, Hache M, Loepke AW. Clinical research into anesthetic neurotoxicity: does anesthesia cause neurological abnormalities in humans? J Neurosurg Anesthesiol 2014; 26: 349-57.

76. Ing C, Hegarty MK, Perkins JW, Whitehouse AJO, DiMaggio CJ, Sun M, et al. Duration of general anaesthetic exposure in early childhood and long-term language and cognitive ability. Br J Anaesth 2017; 119: 532-40.

77. Ing C, Sun M, Olfson M, DiMaggio CJ, Sun LS, Wall MM, et al. Age at exposure to surgery and anesthesia in children and associationwith mental disorder diagnosis. Anesth Analg 2017; 125: 1988-98.

78. Mintz CD, Wagner M, Loepke AW. Preclinical research into the effects of anesthetics on the developing brain: promises and pitfalls. J Neurosurg Anesthesiol 2012; 24: 362-7.

79. Vutskits L, Xie Z. Lasting impact of general anaesthesia on the brain: mechanisms and relevance. Nat Rev Neurosci 2016; $17:$ 705-17.

80. Braun S, Gaza N, Werdehausen R, Hermanns H, Bauer I, Durieux ME, et al. Ketamine induces apoptosis via the mitochondrial pathway in human lymphocytes and neuronal cells. Br J Anaesth 2010; 105: 347-54.

81. Sanders RD, Xu J, Shu Y, Januszewski A, Halder S, Fidalgo A, et al. Dexmedetomidine attenuates isoflurane-induced neurocognitive impairment in neonatal rats. Anesthesiology 2009; 110: 1077-85.

82. De Bellis MD, Keshavan MS, Beers SR, Hall J, Frustaci K, Masalehdan A, et al. Sex differences in brain maturation during childhood and adolescence. Cereb Cortex 2001; 11: 552-7.

83. Rothstein S, Simkins T, Nuñez JL. Response to neonatal anesthesia: effect of sex on anatomical and behavioral outcome. Neuroscience 2008; 152: 959-69.

84. Lee BH, Chan JT, Kraeva E, Peterson K, Sall JW. Isoflurane exposure in newborn rats induces long-term cognitive dysfunction in males but not females. Neuropharmacology 2014; 83: 9-17.

85. Xu C, Tan S, Zhang J, Seubert CN, Gravenstein N, Sumners C, et al. Anesthesia with sevoflurane in neonatal rats: developmental neuroendocrine abnormalities and alleviating effects of the corticosteroid and $\mathrm{Cl}(-)$ importer antagonists. Psychoneuroendocrinology 2015; 60: $173-81$.

86. Jevtovic-Todorovic V, Wozniak DF, Benshoff ND, Olney JW. A comparative evaluation of the neurotoxic properties of ketamine and nitrous oxide. Brain Res 2001; 895: 264-7.

87. Aligny C, Roux C, Dourmap N, Ramdani Y, Do-Rego JC, Jégou S, et al. Ketamine alters cortical integration of GABAergic interneurons and induces long-term sex-dependent impairments in transgenic Gad67-GFP mice. Cell Death Dis 2014; 5: e1311.

88. Boscolo A, Ori C, Bennett J, Wiltgen B, Jevtovic-Todorovic V. Mitochondrial protectant pramipexole prevents sex-specific long-term cognitive impairment from early anaesthesia exposure in rats. Br J Anaesth 2013; 110 Suppl 1: i47-52.

89. Raper J, Alvarado MC, Murphy KL, Baxter MG. Multiple anesthetic exposure in infant monkeys alters emotional reactivity to an acute stressor. Anesthesiology 2015; 123: 1084-92.

90. Gaynor JW, Stopp C, Wypij D, Andropoulos DB, Atallah J, Atz AM, et al. Neurodevelopmental outcomes after cardiac surgery in infancy. Pediatrics 2015; 135: 816-25.

91. McAlpine DD, Mechanic D. Utilization of specialty mental health care among persons with severe mental illness: the roles of demographics, need, insurance, and risk. Health Serv Res 2000; 35: 277-92.

92. Nelson HD, Nygren P, Walker M, Panoscha R. Screening for speech and language delay in preschool children: systematic evidence review for the US Preventive Services Task Force. Pediatrics 2006; 117: e298-319.

93. Samsom JF, de Groot L, Cranendonk A, Bezemer D, Lafeber HN, Fetter WP. Neuromotor function and school performance in 7-year-old children born as high-risk preterm infants. J Child Neurol 2002; 17: 325-32. 